\title{
Study Deskriptif Aktualisasi Diri Mahasiswa dalam Penggunaan Metode PBL (Problem Based Learning) dengan Seven Jump pada Program Studi S1 Keperawatan Fakultas Ilmu Keperawatan Universitas Islam Sultan Agung Semarang
}

\section{Descriptive Study of Self-Actualization OF Students In The Use of PBL (Problem Based Learning) Method With Jump Seven in The Nursing Study Program}

\author{
Siti Alisah ${ }^{1(\mathrm{CA})}$, Nutrisia Nu'im Haiya ${ }^{2}$, Iwan Ardian ${ }^{3}$ \\ ${ }^{1(\mathrm{CA})}$ Program Studi S1 Keperawatan, Fakultas Ilmu Keperawatan, Universitas Islam Sultan Agung \\ Semarang; Sitialisah1509@gmail.com (Corresponding Author) \\ ${ }^{2}$ Fakultas Ilmu Keperawatan, Universitas Islam Sultan Agung Semarang \\ ${ }^{3}$ Fakultas Ilmu Keperawatan, Universitas Islam Sultan Agung Semarang
}

\begin{abstract}
PBL (Problem Based learning), students analyze a problem and new information with scientific evidence. The learning method using the seven jump method can be used by students to hone skills in developing self-actualization that is used to solve a problem. The purpose of this study is to find out the selfactualization of students in the use of the PBL (Problem Based Learning) method with seven jumps in Nursing S1 Study Program, FIK UNISSULA Semarang. This research uses a descriptive method. The sampling technique uses total sampling with a total of 207 respondens. The results were obtained from 207 respondents, 26 respondents $(12,6 \%)$ had high self-actualization, 101 respondents $(48,8 \%)$ had moderate self-actualization, 69 respondents $(33,3 \%)$ were close to self-actualization and 11 respondents $(5,3 \%)$ have low self-actualization. This study found that the most self-actualization description of students in using PBL (Problem Based Learning) method with seven jumps at the Nursing S1 Study Program, Faculty of Nursing, UNISSULA Semarang.
\end{abstract}

\section{Keywords: Self-actualization, Problem Based Learning, Seven Jump}

\begin{abstract}
ABSTRAK
PBL (Problem Based Learning) yaitu mahasiswa menganalisis sebuah masalah dan informasi yang baru dengan adanya bukti ilmiah. Metode pembelajaran dengan menggunakan metode seven jump dapat digunakan mahasiswa untuk mengasah kemampuan dalam mengembangkan aktualisasi diri yang digunakan untuk memecahkan sebuah masalah.

Tujuan penelitian ini mengetahui gambaran aktualisasi diri mahasiswa dalam penggunaan metode PBL (Problem Based Learning) dengan seven jump di Prodi S1 Keperawatan FIK UNISSULA Semarang. Penelitian ini menggunakan metode deskriptif. Teknik pengambilan sampel menggunakan total sampling dengan jumlah responden sebanyak 207 responden. Hasil penelitian diperoleh dari 207 responden, sebanyak 26 responden $(12,6 \%)$ mempunyai aktualisasi diri tinggi, 101 responden $(48,8 \%)$,mempunyai aktualisasi diri sedang, 69 responden $(33,3 \%)$ yaitu mendekati aktualisasi diri dan 11 responden $(5,3 \%)$ mempunyai aktualisasi diri rendah. Penelitian ini didapatkan bahwa gambaran aktualisasi diri mahasiswa dalam penggunaan metode PBL (Problem Based Learning) dengan seven jump di S1 Keperawatan FIK UNISSULA Semarang terbanyak yaitu kategori sedang.
\end{abstract}

Kata Kunci: Aktualisasi diri, Problem Based Learning, Seven Jump 


\section{PENDAHULUAN}

Kurikulum perguruan tinggi saat ini telah mengalami perubahan, dari kurikulum sebelumnya yaitu kurikulum yang berbasis dengan konten menjadi kurikulum yang berbasis pada kompetensi (KBK). Salah satu cara untuk mengubah sistem pendidikan tradisional menjadi pembelajaran berbasis masalah (PBL), kurikulum PBL diperkenalkan pertama kali pada tahun 1969 oleh Fakultas Kedokteran di Universitas McMaster Kanada. Aplikasi mahasiswa keperawatan memprioritaskan proses PBL (Problem Based Learning), dimana mahasiswa membentuk kelompok baru atau tutorial (diskusi kelompok) untuk menganalisis masalah dan informasi baru dan menyelesaikan masalah terkait keperawatan ketika ada bukti ilmiah (Susanti et al., 2017).

PBL (Problem Based Learning) adalah pengembangan pembelajaran digunakan untuk melatih mahasiswa agar kreatif dalam melaksanakan pembelajaran, mereka dapat berpikir kritis dan logis, dan mahasiswa dapat mengkomunikasikan pengetahuan yang jelas dan meningkatkan pemahanan mereka tntang apa yang mereka pelajari pada saat belajar (Susanti et al., 2017).

Pendekatan seven jump digunakan untuk meningkatkan keterampilan dan pengetahuan mahasiswa keperawatan di klinik, membiasakan mahasiswa untuk memiliki sikap percaya diri serta kemampuan untuk daya saing ketika melakukan praktik klinik. Mahasiswa sering menghadapi masalah yang mereka hadapi dalam bentuk kasus nyata di klinik atau memicu kasus, dalam hal ini mahasiswa harus secara aktif bertindak berdasarkan informasi yang diberikan. Metode ini dirancang untuk memastikan bahwa setiap mahasiswa memiliki kecerdasan dan pemahaman tentang konsep teknologi pengetahuan terbaru terkait dengan kasus-kasus penyakit yang sering terjadi selama praktik klinis (Wahyuningsih, 2018).

Penelitian yang dilakukan oleh Ningsih, (2017) tentang aktualisasi diri mahasiswa keperawatan dalam kursus tutorial (Seven Jump) hasil penelitian univariat menunjukkan bahwa pemahaman mahasiswa tentang aktualisasi diri mahasiswa menandakan bahwa sebagian besar (93,8\%) dari aktualisasi diri mahasiswa adalah baik. Metode pembelajaran yang menggunakan tujuh metode lompatan dapat digunakan untuk mengasah kemampuan untuk mengembangkan aktualisasi diri yang digunakan untuk menyelesaikan masalah, termasuk mereka yang pandai mengungkapkan pendapat dan yang dapat mendiskusikan masalah secara lebih menyeluruh, mahasiswa bertanggung jawab atas semua keputusan yang dimbil tanpa adanya pengaruh orang lain (Pajouhandeh, 2013).

Aktualisasi diri setiap individu sangat penting untuk ditingkatkan. Menurut Putra, (2015) mengatakan bahwa semakin tinggi aktualisasi dirinya semakin rendah rasa takut akan sukses. Karakteristik menurut Abraham Maslow tentang seseorang yang sepenuhnya menyadari dirinya adalah bahwa individu dapat melihat kenyataan secara lebih efektif, fokus pada diri dan penerimaan diri, spontanitas, kesederhanaan dan kebiasaan dalam berbagai hal, menarik diri, kesendirian, otonomi: kemandirian dari budaya dan lingkungan, kenyamanan serta penghormatan jangka panjang, persepsi sosial, hubungan antar pribadi, demokrasi, kekuatan yang bermanfaat dan bermoral, kreatif, mandiri, perasaan akan tertawa untuk pengalaman terbaik (Asmadi, 2008). 


\section{METODE}

Penelitian ini adalah menggunakan metode deskriptif dimana peneliti hanya ingin melakukan deskripsi mengenai fenomena yang ditemukan. Adapun yang ingin kita ketahui dalam penelitian ini adalah gambaran aktualisasi diri seorang mahasiswa menggunakan metode PBL (Problem Based Learning) dengan seven jump (Sastroasmoro, 2011). Responden telah menggunakan metode pembelajaran seven jump oleh mahasiswa di FIK UNISSULA Semarang angkatan 2016 dan 2017. Penelitian ini dilaksanakan pada tanggal 08 ktober - 09 ktober 2019 sebanyak 207 responden. Instrumen penelitian menggunakan kuesioner aktualisasi diri. Kuesioner berisi identitas mahasiswa yang meliputi: jenis kelamin, umur, data IPK, tingkat semester dan asal sekolah. Kuesioner aktualisasi diri terdiri dari 28 pertanyaan, skala yang digunakan adalah Skala Likert, dan peringkat yang digunakan dalam survei (SS) sangat sering, (S) sering, (KK) kadang-kadang, (TP) Never, lalu diberi tanda centang $(\sqrt{ })$.

\section{HASIL}

Tabel 1. Distribusi Frekuensi Aktualisasi Diri Responden di FIK UNISSULA Semaarang pada Bulan Oktober $2019(n=207)$

\begin{tabular}{ccc}
\hline Kategori & Frekuensi (f) & Persentase $(\%)$ \\
\hline Tinggi & 26 & 12,6 \\
Sedang & 101 & 48,8 \\
Mendekati & 69 & 33,3 \\
Rendah & 11 & 5,3 \\
\hline Total & 207 & 100 \\
\hline
\end{tabular}

Pada Tabel 1 jumlah responden terbesar adalah mereka yang memiliki banyak kriteria aktualisasi diri sedang sebanyak 101 responden pada persentase 48,8\%, sedangkan responden paling sedikit degan kriteria aktualisasi rendah adalah 11 responden pada persentase 5,3\%, responden dengan aktualisasi diri tinggi sebanyak 26 responden dengan persentase 12,6\% dan responden dengan kriteria untuk mendekati aktualisasi diri sebanyak 69 responden dengan peersentase $33,3 \%$.

\section{PEMBAHASAN}

Ningsih \& Fidora (2018) mengatakan aktualisasi diri adalah keharusan hati nurani dalam melakukan apa yang terbaik bagi manusia. Seorang individu yang dapat menyadari dirinya memahami bahwa ada hambatan yang ada di dalam dirinya, yaitu di dalam (internal) atau di luar (eksternal), sehingga perilaku seseorang ketika melakukan sesuatu disebabkan oleh adanya hambatan tersebut untuk mengontrol. Hambatan yang terjadi di dalam individu adalah faktor internal, dan hambatan yang terjadi di luar individu.

Hasil penelitian ini konsisten dengan penelitian yang disebutkan dalam Potter dan Perry (2005 dalam Azhar Noor, 2014) bahwa salah satu faktor yang memengaruhi aktualisasi diri yaitu faktor eksternal atau lingkungan yang dapat dengan bebas mengekspresikan kemampuan seseorang, seperti mencapai nilai kebenaran, kejujuran, dan keadilan yang didukung oleh lingkungan. 
Aktualisasi diri dari piramida Maslow adalah kebutuhan tertinggi, tetapi beberapa orang yang telah mencapai aktualisasi diri seutuhnya (Azhar Noor, 2014). Hal ini konsisten dengan penelitian Juliandi (2017) mengatakan tentang aktualisasi diri bahwa aktualisasi diri dengan kategori sedang sebagian besar dimiliki oleh mahasiswa, artinya mereka telah berusaha mengembangkan potensi mereka, tetatpi belum maksimal. Kekuatan aktualisasi diri dengan kategori tinggi yang dimiliki oleh setiap mahasiswa masih sangat kecil. Individu yang memanfaatkan potensi meeka sebaik-baiknya adalah mereka yang memiliki kemampuan aktualisasi diri yang tinggi.

Pembelajaran yang merupakan salah satu untuk meningkatkan suatu keaktifan dari mahasiswa tersebut dan untuk meningkatkan aktualisasi diri adalah metode PBL (Problem Based Learning) dengan seven jump. Metode ini merencanakan agar setiap mahasiswa dalam pembellajaran dapat berpikir kritis serta pandai dalam menciptakan, mengaplikasikan bahan pendidikan yang sama. Metode pembelajaran PBL dengan tujuh lompatan meliputi identifikasi bahasa asing, identifikasi masalah, analisis masalah, penataan identifikasi tujuan pembelajaran, durasi belajar mandiri, dan persentase hasil belajar mandiri (Syarif \& Kamil, 2013)

\section{KESIMPULAN}

Hasil dari penelitian didapatkan bahwa gambaran gambaran aktualisasi diri mahasiswa dalam penggunaan metode PBL (Problem Based Learning) dengan seven jump di FIK UNISSULA terbanyak yaitu kategori sedang. Meningkatkan aktualisasi diri dalam penggunaan metode PBL (Problem Based Learning) dengan seven jump ketika berdiskusi dengan metode berkelompok institusional dapat menggunakan penilaian dalam faktor"jujur". Melakukan evaluasi terhadap peeran tutor saat pelaksanaan tutorial seven jump, karena peran tutor dapat mempengaruhi proses pembelajaran PBL dengan seven jump. Pelaksanaan metode PBL (Problem Based Learning) dengan seven jump seharusnya tidak dijalankan pada setiap semester karena mahasiswa akan merasakan bosan dalam melakukan proses tersebut sehingga aktualisasi diri mahasiswa kurang maksimal.

\section{DAFTAR PUSTAKA}

Asmadi. (2008). Konsep Dasar Keperawatan. Editor. Jakarta: EGC.

Azhar Noor, M. S. (2014). Hubungan kepercayaan diri dengan aktualisasi diri pada mahasiswa yang aktif berorganisasi di sekolah tinggi ilmu kesehatan muhammadiyah banjarmasin. Sekolah Tinggi Ilmu Kesehatan Muhammadiyah Banjarmasin. https://id.scribd.com/doc/241748383/ hubungankepercayaan-diri-dengan-aktualisasi-diri-pada-mahasiswa-yang-aktif-berorganisasi-di-sekolah-

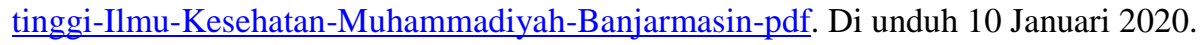

Juliandi, R. (2017). Hubungan konsep diri dengan aktualisasi diri pada mahasiswa program studi ilmu keperawatan universitas tanjungpura pontianak angkatan 2013 dan 2014. Journal of Chemical Information and Modeling, 53(9), 1689-1699. https://doi.org/10.1017/CBO9781107415324.004. Di unduh 08 Januari 2020.

Ningsih, R. (2017). Hubungan peran tutor dengan aktualisasi diri mahasiswa keperawatan dalam proses tutorial (seven jumps) pada prodi ilmu keperawatan di fakultas kesehatan dan mipa universitas muhammadiyah sumatera barat tahun 2016. Menara Ilmu, XI(77), 18-24. https://jurnal.umsb.ac.id/index.php/menarailmu/article/view/289. Di unduh 14 April 2019. 
Ningsih, R., \& Fidora, I. (2018). Peningkatan peran tutor dengan aktualisasi diri mahasiswa keperawatan dalam proses tutorial (seven jumps) pada prodi ilmu keperawatan di fakultas kesehatan dan mipa universitas muhammadiyah sumatera. Menara Ilmu, XII(9), 193-203. https://jurnal.umsb.ac.id/index.php/menarailmu/article/view/1061. Di unduh 20 Mei 2019.

Pajouhandeh, E. (2013). Personal development and self-actualization of students the new environment. International Journal of Research In Social Sciences, 2(1), 21-26. https://doi.org/http://pdfs.semanticscholar.org/031f/c3ac8c56 cb2f0e8a89f8fa90f720d17d.pdf. Di unduh 09 September 2019.

Putra, L. P. (2015). Pengaruh aktualisasi diri dan dukungan sosial terhadap ketakutan akan sukses pada wanita karir. Jurnal Motiva, 22-27. https://doi.org/http://ejurnal.untagsmd.ac.id/index.php/MV/article/view/3493. Di unduh 09 September 2019.

Sastroasmoro, S. (2011). Dasar-dasar metodologi penelitian klinis (4th ed.). Jakarta: Sagung Seto.

Susanti, P. F. E., Lisiswanti, R., Soleha, T. U., Saputra, O., \& Okyafany. (2017). Hubungan Kualitas Skenario Terhadap Keefektifan Diskusi Problem- Based Learning ( PBL ) Blok Emergency Pada Mahasiswa Fakultas Kedokteran Universitas Lampung. Medulla, 7(4), 157-163. http://juke.kedokteran. unila.ac.id/index.php/medula/article/view/1768. Di unduh 02 Mei 2019.

Syarif, H., \& Kamil, H. (2013). Perbandingan Efektifitas Metode Seven Jumps Dengan Metode Interactive Skill Station ( Iss ) Pada Mahasiswa Psik Fk Unsyiah The Comparison Of Effectivity The Seven Jumps Method And Interactive Skill Station Among Nursing Students At School Of Nursing $\quad, \quad$ Syi. Idea Nursing Journal, IV(2), 19-25. http://www.jurnal.unsyiah.ac.id/INJ/article/view/1560. di unduh 10 Mei 2019.

Wahyuningsih, I. S. (2018). eksplorasi evaluasi metode problem based learning melalui pendekatan seven jump method pada mahasiswa keperawatan. Wacana Kesehatan, 3(2), 334-340. http://jurnal.akperdharmawacana.ac.id/ index.php/wacana/article/view/80/46. Di unduh 02 Juni 2019. 